\title{
Estrutura de governança em alianças estratégicas de P\&D geradoras de inovações da Embrapa
}

\section{Taisa Scariot Preusler* (D)}

Priscila Rezende da Costa** (D)

Tatiane Baseggio Crespi ${ }^{* * *}$ (D)

* Universidade Nove de Julho (Uninove), São Paulo, São Paulo, Brasil

E-mail: taisa.s@hotmail.com

** Universidade Nove de Julho (Uninove), São Paulo, São Paulo, Brasil

E-mail: priscilarezende@yahoo.com.br

*** Universidade Nove de Julho (Uninove), São Paulo, São Paulo, Brasil

E-mail: ptatianebaseggiocrespi@gmail.com

Submissão: 77 de dezembro de 2018 Versáo revisada (entregue): I 6 de Setembro de 2019 Aprovado: 04 de Setembro de 2020

\section{Resumo}

Com o crescimento populacional e o aumento da expectativa de vida, as inovaçóes são o principal meio de otimizar a produção agropecuária. Doravante, a formação de alianças pode ser uma alternativa para potencializar a base de recursos pró-inovação das organizaçóes envolvidas nesses desafios. Sendo assim, neste estudo, objetivou-se compreender como as alianças estratégicas de $\mathrm{P} \& \mathrm{D}$ são estruturadas para promover inovaçóes agropecuárias. Três alianças, envolvendo a Empresa Brasileira de Pesquisa Agropecuária (Embrapa) e parceiros, constituíram a unidade de análise da pesquisa. Sobre a estruturação e a formalização das alianças analisadas, foi possível concluir que elas são dimensionadas, inicialmente, conforme a natureza dos atores envolvidos, embora tenha se constatado que seus níveis são alterados também pelo escopo, prazo e natureza das atividades praticadas.

PaLAVRAS-CHAVE | Alianças estratégicas; P\&D; Embrapa; Inovaçóes agropecuárias 


\title{
R\&D Strategic Alliances in Embrapa and the Generation of Agricultural Innovations
}

\begin{abstract}
With population growth and increasing life expectancy, innovations are the main means of optimizing agricultural production. From now on, the formation of alliances can be an alternative to strengthen the pro-innovation resource base of the organizations involved in these challenges. Thus, the objective was to understand how R\&D strategic alliances are structured to promote agricultural innovations. Three alliances, involving the Brazilian Agricultural Research Corporation (Embrapa) and partners, constituted the research analysis unit. On the structuring and formalization of alliances analyzed, it was possible to conclude that they are initially dimensioned considering the nature of the actors involved; however, other dimensions also altered the levels of structuring and formalization, including the scope, term and nature of the activities practiced in the alliances..
\end{abstract}

KEYwORDs | Strategic alliances; R\&D; Embrapa; Agricultural innovations 


\section{Introdução}

O Sistema Nacional de Pesquisa Agropecuária (SNPA) tem a missão de viabilizar soluções de pesquisa, de desenvolvimento e de inovação para a sustentabilidade da agricultura, em benefício da sociedade brasileira. Foi instituído pela Portaria $\mathrm{n}^{\circ}$ 193, de 7 de agosto de 1992 (BRASIL, 1992), haja vista o importante papel que a inovação agropecuária desempenha no país.

As alianças estratégicas têm sido consideradas uma alternativa estrutural à inovação, tendo em vista a possibilidade de complementação de recursos, de acesso a novos mercados e de redução de custos (DYER; SINGH, 1998; ALMEIDA; COSTA, 2017). Sua formação, no entanto, é um processo complexo, e constantemente ameaçado por comportamentos oportunistas, capazes de provocar impactos negativos em seu desempenho e de gerar insucessos. Por isso, é essencial que seja desenvolvida uma gestão adequada (SHAKERI; RADFAR, 2017; JAP; ANDERSON, 2003), preocupada em firmar contratos bem elaborados, com as devidas salvaguardas e mençóes a direitos e deveres das partes, apta a provisionar, inclusive, açôes de enfretamento a eventuais problemas futuros (ARGYRES; MAYER, 2007).

As chances de sucesso de uma aliança podem aumentar, promovendo vantagens a todas as partes envolvidas (WANG et al., 2015), se as instituiçóes adotarem as práticas de: (a) trocar continuamente informaçôes e conhecimentos com os parceiros (SHAKERI; RADFAR, 2017; PATTERSON; AMBROSINI, 2015); (b) estabelecer uma estrutura de governança para a gestáo das alianças (HEIMERIKS; DUYSTERS, 2007; MILAGRES; REZENDE; SILVA, 2017); (c) selecionar os parceiros apropriados, gerenciando conflitos e criando confiança mútua (SHAKERI; RADFAR, 2017); e (d) gerar mecanismos de proteção de ativos (SORRENTINO; GARRAFFO, 2012).

Vale ressaltar que os processos de gestão estratégica das alianças integram o construto da capacidade relacional (CR) (SCHILKE; GOERZEN, 2010), cujos resultados potenciais são as chamadas rendas relacionais, ou seja, benefícios, em termos de ganhos econômicos; e resultados científicos e tecnológicos, que somente são obtidos por meio de uma relação interorganizacional (ZHANG; LI; LI, 2017).

Além disso, a estrutura de governança pode se manifestar, de forma distinta, em empresas públicas de pesquisa, que estabelecem alianças de pesquisa e de desenvolvimento de $\mathrm{P} \& \mathrm{D}$ com parceiros externos, incluindo as categorias lineares das instituiçóes parceiras, como: empresas privadas, organizações públicas de pesquisa, cooperativas de produtores, associaçóes de produtores, dentre outras (CARAYOL, 2003; LHUILLERY; PFISTER, 2009; APPIO et al., 2017). 
Entre as várias instituiçóes vinculadas direta ou indiretamente às atividades de pesquisa agropecuária, que constituem o SNPA, estão as Organizaçóes Estaduais de Pesquisa Agropecuária (Oepas), compostas por institutos de pesquisa e universidades, tanto estaduais quanto federais, públicos e privados; e a Empresa Brasileira de Pesquisa Agropecuária (Embrapa), coordenadora e principal agente desse sistema, cujo principal objetivo é proporcionar soluçóes para auxiliar o desenvolvimento sustentável, por meio da produção, da adaptação e da transferência das tecnologias e de conhecimentos ao setor de produção (VIEIRA FILHO; PINTO VIEIRA, 2013).

Com diversos projetos científicos e tecnológicos, voltados a vencer as barreiras existentes na produção de alimentos, de fibras e de energia, a Embrapa é um exemplo bem-sucedido no que diz respeito ao estabelecimento de alianças estratégicas, públicas e privadas, em nível nacional e internacional, com produtores, universidades, instituiçôes de pesquisas, organizaçôes intermediárias etc.

A fim de integrar os distintos conhecimentos da cadeia produtiva (DUTRÉNIT; VERA-CRUZ, 2018) e de ampliar a capacidade de geração de inovaçóes, os resultados alcançados pela Embrapa são transferidos à sociedade, na forma da criação de produtos, de tecnologias e de novas metodologias; bem como da publicaçáo de livros, relatórios técnicos, artigos científicos e de orientação acadêmica (DOSSA; SEGATTO, 2010), gerando, com isso, benefícios não apenas econômicos, mas de cunho social e ambiental (EMBRAPA, 2019).

A título de exemplificação, entre os anos de 2000 e 2007, das 150 novas cultivares de soja lançadas pela Embrapa, 145 foram desenvolvidas com parceiros externos, como multinacionais (Monsanto, Basf, entre outras), fundaçóes, cooperativas, Oepas, etc., sob o incentivo, principalmente, da Lei de Proteção de Cultivares, promulgada no final da década de 1990 (FIGUEIREDO, 2016).

Em 2015, os números de contratos ativos de parcerias com a Embrapa totalizavam 3.185, distribuídos entre convênios, contratos de cooperação técnica e cooperação geral. As alianças são formadas para o desenvolvimento de: insumos (36\%), processos tecnológicos $(27 \%)$, cultivares (18\%), equipamentos (10\%), banco de dados $(3 \%)$, softwares (3\%), e mapeamento e zoneamento (3\%) (EMBRAPA, 2019).

Em virtude da sua capacidade de difusão e de transferência de conhecimento e de tecnologia, voltados ao sistema agrícola, a contribuição da Embrapa, portanto, é preponderante no âmbito da pesquisa e da inovação. Sendo assim, este estudo tem como objetivo analisar como as alianças estratégicas de P\&D da Embrapa são estruturadas para promover inovações agropecuárias. 


\section{Referencial teórico}

A capacidade de gestâo de alianças estratégicas, nomeada de capacidade relacional (CR), é aqui investigada, a partir da perspectiva da capacidade dinâmica (SCHILKE; COOK, 2015; NIESTEN; JOLINK, 2015) de uma dada instituiçāo, que, por meio de processos organizacionais, busca criar, expandir ou transformar a base de recursos (HELFAT et al., 2009), possibilitando às empresas lidar com a mudança de ambientes.

Schilke e Goerzen (2010) estabeleceram como antecedentes da CR a experiência no estabelecimento e a estrutura de governança das alianças. A experiência prévia, acumulada pela formação de alianças estratégicas anteriores, possibilita às organizaçôes o desenvolvimento da habilidade de escolher parceiros em potencial, a fim de complementar os recursos; de gerenciar (HEIMERIKS; DUYSTERS, 2007; ALMEIDA; COSTA, 2017) e de realizar ajustes, quando necessários (HEIMERIKS; DUYSTERS, 2007). Desse modo, empresas que detêm uma estrutura voltada à administração das alianças conseguem centralizar as informaçôes, facilitar a comunicação entre os setores (HOANG; ROTHAERMEL, 2005), desenvolvendo meios para gerir essas alianças de forma mais eficiente (HEIMERIKS; DUYSTERS, 2007). Sobre a estrutura de governança da aliança, destaca-se a sua formalização, ou seja, os diferentes níveis relacionados à proteçâo de ativos (SORRENTINO; GARRAFFO, 2012), considerando os parceiros e os objetos das alianças.

Como o conhecimento externo desempenha um papel táo importante quanto o interno, para as instituiçôes, é fundamental buscar P\&D e oportunidades no mercado, por intermédio de diferentes canais (CHESBROUGH, 2006). Assim, cada vez mais instituições têm formado alianças estratégicas de P\&D para a realizaçâo de atividades exploratórias de: pesquisa básica e/ou aplicada, invenção, desenvolvimento experimental, tomada de risco e construção de novas capacidades. A intenção é conseguir a colaboração entre diferentes atores, com habilidades, origens e experiências advindas das mais diversificadas bases de conhecimento, e outros recursos necessários à geração de inovaçôes (POWELL; KOPUT; SMITH-DOERR, 1996).

As alianças de $\mathrm{P} \& \mathrm{D}$, especificamente, podem ser formadas pela união entre: (1) empresas e indústrias, promovendo os conhecimentos de mercado e industrial; e (2) instituições públicas e privadas, como universidades, organizações e institutos de pesquisa, gerando o conhecimento científico (DU; LETEN; VANHAVERBEKE, 2014). 
Vale destacar que a parceria entre instituiçôes públicas e privadas é vista como uma alternativa à inovação, já que ela é capaz de: (a) antecipar demandas; (b) dar respostas mais rápidas às mudanças do mercado (WANG et al., 2015); (c) reduzir custos; (d) acessar novos mercados e oportunidades (DING; DEKKER; GROOT, 2013; WANG et al., 2015); (e) desenvolver e aprimorar competências essenciais, por meio de recursos complementares, conseguidos com organizaçóes parceiras (POWELL; KOPUT; SMITH-DOERR, 1996); (f) reconfigurar os próprios recursos (WANG et al., 2015); e (g) dar acesso: ao conhecimento científico de fronteira, com baixo custo (ETZKOWITZ, 2017); ao conhecimento codificado, isto é, aquele que ainda não foi publicado (FABRIZIO, 2009); a equipamentos científicos avançados, que são mais dispendiosos; e a instalaçôes, para conduzir pesquisas de ponta (LETEN et al., 2013).

Além das contribuiçóes específicas, citadas anteriormente, as alianças podem gerar: aumento de novos produtos em desenvolvimento; crescimento e diversificação das instituçóes, em longo prazo (KAUPPILA, 2015); invençóes com maior significado técnico e de mais fácil comercialização (WALSH; LEE; NAGAOKA, 2016); e, ainda, rendas relacionais, isto é, benefícios, em termos de ganhos econômicos, e resultados científicos e tecnológicos, obtidos na relação interorganizacional (ZHANG; LI; LI, 2017).

Para alcançar as vantagens mencionadas, a formação de alianças de P\&D, no entanto, precisa superar algumas barreiras, entre as quais estáo: a apropriação (GULATI; SINGH, 1998), os objetivos divergentes e as rivalidades (POWELL; KOPUT; SMITH-DOERR, 1996), e o oportunismo (JAP; ANDERSON, 2003; SHAKERI; RADFAR, 2017).

Quando a aliança envolve parceiros de natureza distinta, corre-se o risco, também, de haver custos mais elevados para a coordenação, tendo em vista a dificuldade de comunicação, as distâncias geográficas, as diferenças culturais ou, ainda, a não concordância de açôes estratégicas para a invenção e a inovação (CUMMINGS; KIESLER, 2007).

Esses obstáculos podem ser vencidos por uma gestão adequada das alianças, também conhecida como capacidade relacional (KALE; DYER; SINGH, 2002). Então, quanto maior é a capacidade de gestão de alianças de uma instituição, mais chances ela terá de aprimorar sua estrutura de governança (FAEMS; VAN LOOY; DEBACKERE, 2005), da qual fazem parte departamentos especializados, treinamento, avaliação de procedimentos e ferramentas codificadas (diretrizes, manuais, check lists, modelos de contrato, etc.) (HEIMERIKS; DUYSTERS, 2007). 
Além disso, esses mecanismos possibilitam a centralização e a codificação do aprendizado com a experiência das alianças, a fim de realizar adaptações e melhorias em alianças futuras, ou, ainda, que as práticas mais eficientes sejam disseminadas e replicadas (SLUYTS et al., 2011; MILAGRES; REZENDE; SILVA, 2017), evitando a sobreposição de acordos, e proporcionando o intercâmbio de experiências entre os gestores envolvidos (SLUYTS et al., 2011).

Outro fator influenciador, que faz parte da estrutura de governança e contribui para o sucesso de uma aliança, está relacionado à sua fase inicial (contratos) de formalização. De modo geral, os instrumentos jurídicos são compostos por cláusulas contratuais, as quais especificam os direitos e as responsabilidades de cada parte, bem como os resultados a serem entregues, os procedimentos de controle e de solução de conflitos, as penalidades (em caso de não cumprimento das atividades estabelecidas) (POPPO; ZENGER, 2002), e as cláusulas de rescisão (LUO; TAN, 2003), sendo possível, ainda, desenvolver mecanismos de proteçấo de investimentos e de propriedade intelectual (FAEMS; VAN LOOY; DEBACKERE, 2005).

O nível de complexidade de um contrato é estabelecido pelos riscos das atividades envolvidas nas parcerias. Assim, contratos mais complexos tendem a ser mais específicos e inclusivos (DING; DEKKER; GROOT, 2013), isto é, a ter um maior número de cláusulas e de acordos, que especificam, com maior detalhamento, termos e provisões, para gerenciar e monitorar os riscos da transação (LUO; TAN, 2003), fazendo, com isso, que as ocorrências de oportunismo diminuam (DING; DEKKER; GROOT, 2013).

Além disso, os instrumentos jurídicos servem de suporte para a coordenação e a adaptação das atividades entre os parceiros, uma vez que são realizadas tarefas interdependentes, em que açóes ou saídas de um parceiro estão condicionadas a ações ou saídas de outro. Tal interdependência aumenta a necessidade de uma coordenação eficiente, já que as divisóes de trabalho precisam ser harmonizadas; e de um alto nível de comprometimento e de competência, com fins de alinhar interesses, expectativas, açóes e atividades (GULATI; SINGH, 1998). Portanto, instituiçóes que conseguem desenvolver uma estrutura de governança interna e a formalização adequada das alianças elevam as chances de sucesso dessas parcerias.

\section{Método}

Para alcançar o objetivo deste estudo, foi realizada uma pesquisa de natureza qualitativa, sendo a fonte de dados constituída pelo ambiente do fenômeno; e o 
pesquisador, um instrumento fundamental para a coleta, a seleção, a verificação e a interpretação desses dados (CRESWELL, 2017).

A abordagem foi exploratória, por meio de um processo de interação entre o pesquisador, os participantes e os locais estudados (MARCONI et al., 2006). A opção pelo estudo de caso, para compor o método utilizado, deu-se em função de não haver domínio do pesquisador sobre o fenômeno estudado, o que permitiu verificar, ligar e comparar as informações obtidas (conhecimento prático) às proposições do estudo (conhecimento teórico) (GODOY, 1995).

A unidade de análise escolhida para a investigação do problema foi a Embrapa, por atender os seguintes critérios: (a) é reconhecida como um dos principais atores da pesquisa agropecuária brasileira; (b) possui experiência na formação de alianças para o desenvolvimento de inovaçoos agropecuárias; e (c) denota evidências de capacidade relacional, pois promove a integração e interaçóes entre os diferentes atores do SNPA, incluindo organizaçóes com fins lucrativos (empresas, cooperativas, institutos de pesquisa privados) e sem esses fins (universidades públicas, institutos de pesquisa públicos e organizaçóes sociais).

Para compor o estudo de caso Embrapa, foram selecionadas três alianças, analisadas a partir dos seguintes fundamentos: alianças estratégicas de P\&D, geradoras de inovaçôes de relevância social, econômica ou ambiental, celebradas nos últimos 15 anos. A escolha desse período se deve ao fato de que, no histórico da Embrapa, há pesquisas de longo prazo (como é o caso das cultivares, plantadas, em média, a cada 12 anos), que foram incluídas neste estudo.

A pesquisa foi iniciada por uma consulta, no site da Embrapa, à categoria de produtos, processos e serviços (https://www.embrapa.br/produtos-processos-e-servicos), sobre as soluçóes tecnológicas desenvolvidas pela empresa. Ao aplicar o filtro para o período compreendido entre 2002 a 2017, o site apresentou um total de 1.794 tecnologias, geradas somente pela Embrapa e entre a Embrapa e parceiros externos. Posteriormente, houve consulta acerca das cultivares em nome da Embrapa, no Registro Nacional de Cultivares (RNC), pelo site (http://www.agricultura.gov. br/guia-de-servicos/registro-nacional-de-cultivares-rnc), que apontou, em janeiro de 2017, 1.580 cultivares registradas, aproximadamente. E, por fim, buscou-se, no site do Instituto Nacional da Propriedade Industrial (http://www.inpi.gov.br/), as patentes registradas ou com pedido de registro pela Embrapa.

Tomando por base as alianças estratégicas para o desenvolvimento de tecnologias, formadas pela Embrapa com parceiros externos, foram selecionadas, para a 
realização deste estudo, de forma intencional, três alianças de $\mathrm{P} \& \mathrm{D}$, discriminadas no Quadro 2.

Em relaçáo à coleta de dados, foram realizadas entrevistas, a partir de um roteiro semiestruturado, conforme o modelo de Schilke e Goerzen (2010), sendo todas elas gravadas, totalizando seis horas e quarenta e oito minutos de gravação. Foram dez entrevistas: três com os chefes de Transferência de Tecnologias (T\&T) das Unidades, cujas inovaçóes foram selecionadas; uma com o chefe-geral da Unidade de Recursos Genéticos e Biológicos (Cenargen); e seis com pesquisadores, que tiveram a participação direta, tanto em atividades de P\&D como na coordenação das alianças selecionadas, sendo três da Embrapa e três das instituiçóes parceiras.

Com exceção da entrevista com o pesquisador da Fundação Agrária de Pesquisa Agropecuária (Fapa), realizada via Skype, todas as outras aconteceram presencialmente. Entrevistou-se, ainda, a Coordenadora de Apoio à Inovação e Propriedade Intelectual da Embrapa, por telefone, a fim de identificar as características relacionadas à formação de alianças da empresa, além de entender as questôes de propriedade intelectual e o tempo de duração das alianças com objetivos diferentes.

A observação também foi utilizada por este estudo e registrada em diário de campo, já que ela possibilita ao pesquisador identificar e coletar informaçôes a respeito do ambiente, das expressōes, dos comportamentos, dos fatos e dos sentidos dos indivíduos, no momento das entrevistas in loco (ZAMBERLAN et al., 2014; GODOY, 1995).

Foram também obtidos dados secundários, pelos sites da Embrapa e dos seus parceiros, a partir da consulta de cultivares registradas em nome da Embrapa, e do levantamento e da confirmação de informaçôes de patentes. Além disso, houve a análise de documentos, como contratos, projetos, fôlderes, arquivos, relatórios, atas de reuniōes, regulamentos, jornais e revistas.

Com as distintas fontes de dados, foi possível analisar os tópicos, a partir de diferentes pontos de vista e da comparação entre eles, a fim de ter conclusóes mais consistentes - procedimento denominado "triangulação" (ZAMBERLAN et al., 2014). As informaçóes, coletadas por meio das entrevistas, foram estudadas pela técnica de análise de conteúdo, possibilitando, com isso, a sua organização e classificação, de forma quantitativa, por intermédio de categorias sistematizadas, o que, por sua vez, auxilia na redução dos dados coletados e garante maior precisão das informaçôes (MARCONI et al., 2006).

A síntese da matriz de amarração pode ser verificada no Quadro 1. 
QUADRO 1

Matriz metodológica de amarraçáo

\begin{tabular}{|l|l|}
\hline Natureza & Qualitativa (CRESWELL, 2017) \\
\hline Abordagem & Exploratória (MARCONI et al., 2006) \\
\hline Método & Estudo de caso (GODOY, 1995) \\
\hline Contexto da pesquisa & Embrapa \\
\hline Unidade de análise & $\begin{array}{l}\text { Três alianças estratégicas de P\&D entre a Embrapa e } \\
\text { parceiros externos }\end{array}$ \\
\hline Procedimentos de coleta de dados & $\begin{array}{l}\text { Entrevista, análise documental (contratos e projetos), e } \\
\text { observação não participante (diário de campo). }\end{array}$ \\
\hline Procedimentos de análise de dados & Análise de conteúdo e triangulação. \\
\hline \multicolumn{2}{|l|}{ Principais perguntas } \\
\hline
\end{tabular}

Qual é a percepçáo da instituiçáo em relaçáo à formaçáo de parcerias para a realizaçáo de $P \& D$ ? $\bullet$ Quais conhecimentos, recursos ou ativos específicos sáo buscados, quando se formam parcerias com universidades, empresas privadas, organizaçóes sociais, cooperativas, etc.? • Existem critérios para a seleçáo dessas instituiçóes? • Como se dá o processo de formaçáo das alianças? • De forma geral, a iniciativa da formaçáo da parceria para realizaçáo de $P \& D$ parte da sua instituiçáo ou do parceiro? Em sua opiniáo, por qual motivo? • A instituiçáo possui um departamento formal e/ou estrutura e/ou pessoa que auxilia na gestáo das parcerias firmadas para realizaçáo de $P \& D$, para a geraçáo de novas tecnologias? • As diretrizes para a formalizaçáo de parcerias estáo documentadas em manuais, normas, guia, etc.? • Existe diferenciaçáo na formalizaçáo de parcerias para pesquisa e parcerias para desenvolvimento? - Qual o perfil predominante dos atores externos, envolvidos em pesquisa e dos atores para desenvolvimento? - Sáo celebrados instrumentos contratuais de curto ou médio prazo? • A instituiçáo adota mecanismos para evitar o comportamento oportunista, roubo de informaçóes, conhecimentos unilaterais? - Sáo celebrados termos de confidencialidade e documentos para a proteçáo de informaçóes? - Quais itens sáo considerados essenciais para proporcionar "salvaguarda contratual"? • O nível de formalizaçáo das parcerias é padronizado ou existem diferenças, de acordo com o objeto da aliança ou a natureza do parceiro? Se existem diferenças, favor explicar. • A prática continuada (experiência) no estabelecimento de parcerias para a realizaçáo de $P \& D$ contribui para o desenvolvimento da capacidade relacional da sua instituiçáo, ou seja, da capacidade de gestáo estratégica das parcerias firmadas para a inovação? • É comum haver a repetiçáo de parcerias com o mesmo parceiro? Principalmente para a realizaçáo de pesquisa ou desenvolvimento? Por qual motivo?

Fonte: Elaborado pelos autores.

\section{Resultados e discussões}

Os resultados referem-se à análise das três alianças estratégicas, celebradas entre a Embrapa e parceiros externos, que geraram três inovaçóes: (1) embalagens anatômicas para frutas; (2) cultivar de cevada BRS Quaranta; e (3) inseticida biológico INOVA-Bti.

No Quadro 2 está uma síntese das categorias de análise, tendo como evidências descritoras as alianças investigadas em profundidade. 
QUADRO 2

Síntese das características das alianças estratégicas de $\mathrm{P} \& \mathrm{D}$ investigadas

\begin{tabular}{|c|c|c|c|}
\hline \multirow[b]{2}{*}{ Características } & \multicolumn{3}{|c|}{ Descriçáo sintetizada } \\
\hline & $\begin{array}{l}\text { Aliança (1) } \\
\text { Embalagens anatômicas } \\
\text { para frutas: inovação de } \\
\text { processo }\end{array}$ & $\begin{array}{l}\text { Aliança (2) } \\
\text { Cultivar de cevada BRS } \\
\text { Quaranta: inovação de } \\
\text { produto }\end{array}$ & $\begin{array}{l}\text { Aliança (3) } \\
\text { INOVA-Bti (inseticida } \\
\text { biológico): inovação de } \\
\text { produto }\end{array}$ \\
\hline $\begin{array}{l}\text { Atividades de } \\
P \& D\end{array}$ & $\begin{array}{l}\text { Levantamento dos } \\
\text { problemas encontrados } \\
\text { pelos produtores } \\
\text { para transporte e } \\
\text { armazenamento de frutas } \\
\text { e hortaliças; seleção da } \\
\text { fibra mais adequada para } \\
\text { formaçáo do compósito. } \\
\text { Agregar fibra no } \\
\text { compósito; modelagem e } \\
\text { design das embalagens. }\end{array}$ & $\begin{array}{l}\text { Experimentação para } \\
\text { avaliação do desempenho } \\
\text { agronômico das linhagens. } \\
\text { Melhoramento genético } \\
\text { da cevada. }\end{array}$ & $\begin{array}{l}\text { Indicação de estirpes; } \\
\text { otimização do processo } \\
\text { de produção das estirpes; } \\
\text { desenvolvimento de } \\
\text { formulaçóes de alta } \\
\text { qualidade, e avaliação da } \\
\text { toxidade dos produtos. }\end{array}$ \\
\hline $\begin{array}{l}\text { Principais } \\
\text { parceiros e } \\
\text { natureza }\end{array}$ & $\begin{array}{l}\text { Instituto de } \\
\text { Macromoléculas (IMA) } \\
\text { e Instituto Nacional de } \\
\text { Tecnologia (INT). }\end{array}$ & $\begin{array}{l}\text { Companhia de Bebidas } \\
\text { das Américas (AmBev) } \\
\text { e Fundação Agrária de } \\
\text { Pesquisa Agropecuária } \\
\text { (Fapa). }\end{array}$ & $\begin{array}{l}\text { Instituto Mato-Grossense } \\
\text { do Algodão (IMAmt) } \\
\text { e Cooperativa Mista } \\
\text { de Desenvolvimento } \\
\text { do Agronegócio } \\
\text { (Comdeagro). }\end{array}$ \\
\hline Tema associado & $\begin{array}{l}\text { Agroindústria, segurança } \\
\text { alimentar, nutrição e } \\
\text { saúde. }\end{array}$ & $\begin{array}{l}\text { Agricultura familiar, } \\
\text { agroindústria, melhora- } \\
\text { mento genético e } \\
\text { produção vegetal. }\end{array}$ & $\begin{array}{l}\text { Bioprodutos, formulações } \\
\text { e congêneres. }\end{array}$ \\
\hline $\begin{array}{l}\text { Ano de início } \\
\text { e duraçáo da } \\
\text { parceria }\end{array}$ & $\begin{array}{l}2010 \text { ( } 5 \text { anos de duraçáo; } \\
\text { portanto, médio } \\
\text { prazo, segundo padrão } \\
\text { Embrapa). }\end{array}$ & $\begin{array}{l}2002 \text { (12 anos de } \\
\text { duração; portanto, longo } \\
\text { prazo, segundo padrão } \\
\text { Embrapa). }\end{array}$ & $\begin{array}{l}2016 \text { ( } 1 \text { ano de duraçáo; } \\
\text { portanto, curto prazo, se- } \\
\text { gundo padrão Embrapa). }\end{array}$ \\
\hline $\begin{array}{l}\text { Instrumento de } \\
\text { formalizaçáo }\end{array}$ & Termo de convênio & $\begin{array}{l}\text { Contrato de cooperação } \\
\text { técnica e financeira }\end{array}$ & $\begin{array}{l}\text { Contrato de cooperação } \\
\text { técnica }\end{array}$ \\
\hline $\begin{array}{l}\text { Objetivo da } \\
\text { aliança }\end{array}$ & $\begin{array}{l}\text { Desenvolvimento de } \\
\text { embalagens valorizáveis } \\
\text { para o acondicionamento } \\
\text { de frutas e hortaliças. }\end{array}$ & $\begin{array}{l}\text { Estabelecer as condições } \\
\text { para a cooperação técnica } \\
\text { e financeira entre a } \\
\text { Embrapa, a AmBev e a } \\
\text { Fapa, para a obtenção de } \\
\text { novas cultivares de cevada. }\end{array}$ & $\begin{array}{l}\text { Desenvolvimento de } \\
\text { produtos à base de } \\
\text { Bacillus thuringiensis var. } \\
\text { israelenses e de Bacillus } \\
\text { sphaericus, para controle } \\
\text { de Simulium spp, Culex } \\
\text { quinquefasciatua, Anopheles } \\
\text { spp e Aedes aegypti. }\end{array}$ \\
\hline $\begin{array}{l}\text { Composiçáo } \\
\text { do recurso } \\
\text { financeiro }\end{array}$ & $\begin{array}{l}\text { BNDES: } \\
\text { R\$7.500.217,00; } \\
\text { IMA, INT e Embrapa: } \\
\text { R\$4.179.000,00 (aporte). }\end{array}$ & $\begin{array}{l}\mathrm{R} \$ 4.199 .195,30, \text { sendo } \\
\text { que } \mathrm{R} \$ 1.568 .972,30 \text { se } \\
\text { referem à participação } \\
\text { da Embrapa; } \\
\mathrm{R} \$ 1.362 .612,00, \\
\text { da AmBev; e } \\
\mathrm{R} \$ 1.267 .611,00 \text {, da Fapa. }\end{array}$ & $\begin{array}{l}\text { Sem repasse de recursos } \\
\text { financeiros entre as } \\
\text { instituiçóes. Valores } \\
\text { aportados: R\$ } 120.000,00 \\
\text { (Embrapa); R\$ 60.000,00 } \\
\text { (IMAmt); R\$ 60.000,00 } \\
\text { (Comdeagro). }\end{array}$ \\
\hline
\end{tabular}




\section{QUADRO 2}

Síntese das características das alianças estratégicas de $P \& D$ investigadas

\begin{tabular}{|c|c|c|c|}
\hline $\begin{array}{l}\text { Papel da } \\
\text { Embrapa }\end{array}$ & $\begin{array}{l}\text { Levantamentos das } \\
\text { necessidades de cada } \\
\text { produto; características } \\
\text { apropriadas das } \\
\text { embalagens. }\end{array}$ & $\begin{array}{l}\text { Atividades de } \\
\text { cruzamentos; avanço } \\
\text { de geraçóes; seleção de } \\
\text { progênies; realizaçáo de } \\
\text { testes de avaliação e de } \\
\text { valor de cultivo e uso } \\
\text { (VCU). }\end{array}$ & $\begin{array}{l}\text { Obter as autorizaçóes } \\
\text { necessárias ao } \\
\text { cumprimento da } \\
\text { legislação de acesso ao } \\
\text { patrimônio genético; } \\
\text { responsabilização } \\
\text { pelas atividades do } \\
\text { plano de trabalho; e } \\
\text { disponibilização das } \\
\text { estirpes a serem utilizadas } \\
\text { no contrato. }\end{array}$ \\
\hline $\begin{array}{l}\text { Papel do } \\
\text { Parceiro } 1\end{array}$ & $\begin{array}{l}\text { Parceiro IMA: selecionar, } \\
\text { tratar e caracterizar } \\
\text { rejeitos agrícolas, que } \\
\text { pudessem ser utilizados } \\
\text { nos compósitos } \\
\text { polímeros; selecionar os } \\
\text { materiais poliméricos mais } \\
\text { adequados à preparaçáo } \\
\text { dos compósitos. }\end{array}$ & $\begin{array}{l}\text { Parceiro AmBev: realizar } \\
\text { testes de avaliação de } \\
\text { qualidade de malte } \\
\text { e cerveja, e validar } \\
\text { desempenho agronômico } \\
\text { de cultivares registradas } \\
\text { em nome da Embrapa. }\end{array}$ & $\begin{array}{l}\text { Parceiro IMAmt: } \\
\text { disponibilizar recursos } \\
\text { humanos para a } \\
\text { execução do contrato, } \\
\text { responsabilizando-se pelo } \\
\text { pagamento das despesas; } \\
\text { contratar pesquisador; } \\
\text { comprar (materiais de } \\
\text { consumo e equipamentos) } \\
\text { e contratar serviços. }\end{array}$ \\
\hline $\begin{array}{l}\text { Papel do } \\
\text { Parceiro } 2\end{array}$ & $\begin{array}{l}\text { Parceiro INT: } \\
\text { desenvolvimento dos } \\
\text { projetos das embalagens } \\
\text { primárias, secundárias e } \\
\text { terciárias, no campo do } \\
\text { Design. }\end{array}$ & $\begin{array}{l}\text { Parceiro Fapa: realizar } \\
\text { testes de avaliação de } \\
\text { qualidade de malte } \\
\text { e cerveja; validar } \\
\text { desempenho agronômico } \\
\text { de cultivares registradas } \\
\text { em nome da Embrapa, } \\
\text { e testes de avaliação e } \\
\text { de VCU, em linhagens } \\
\text { desenvolvidas pela } \\
\text { Embrapa. }\end{array}$ & $\begin{array}{l}\text { Parceiro Comdeagro: } \\
\text { obter autorizaçóes } \\
\text { necessárias para regular } \\
\text { o cumprimento da } \\
\text { legislaçáo de acesso ao } \\
\text { patrimônio genético; } \\
\text { responsabilizar-se pela } \\
\text { gestão do processo de } \\
\text { obtençáo dos registros } \\
\text { dos produtos junto às } \\
\text { autoridades competentes; } \\
\text { e produzir o bioinseticida. }\end{array}$ \\
\hline $\begin{array}{l}\text { Principais } \\
\text { aplicaçóes }\end{array}$ & $\begin{array}{l}\text { Transporte e } \\
\text { armazenamento de frutas }\end{array}$ & Cultura de inverno & $\begin{array}{l}\text { Reservatórios de água } \\
\text { para o consumo; locais } \\
\text { apropriados para a } \\
\text { proliferação, ou ligados a } \\
\text { outros meios de controle } \\
\text { do mosquito. }\end{array}$ \\
\hline $\begin{array}{l}\text { Síntese dos } \\
\text { impactos } \\
\text { econômicos, } \\
\text { ambientais e/ou } \\
\text { sociais }\end{array}$ & $\begin{array}{l}\text { Diminuição de perdas e } \\
\text { desperdícios das frutas; } \\
\text { aumento da eficiência no } \\
\text { trabalho; decomposiçáo } \\
\text { mais rápida na natureza. }\end{array}$ & $\begin{array}{l}\text { Aumento de } \\
\text { produtividade; dispensa } \\
\text { parcial ou total das } \\
\text { aplicaçóes de fungicida. }\end{array}$ & $\begin{array}{l}\text { Controle das larvas do } \\
\text { mosquito Aedes aegypti, } \\
\text { transmissor do vírus da } \\
\text { Dengue, Chikungunya } \\
\text { e Zika; não prejudica o } \\
\text { meio ambiente. }\end{array}$ \\
\hline
\end{tabular}

Fonte: Elaborado pelos autores. 
A seguir, são apresentados os resultados e as discussôes sobre a estrutura de governança, considerando as três alianças estratégicas de $\mathrm{P} \& \mathrm{D}$, geradoras de inovaçôes da Embrapa, e seus principais parceiros.

\subsection{Embalagens anatômicas para frutas: uma inovação de processo}

Na Embrapa Agroindústria de Alimentos, a área responsável por formalizar, gerir administrativamente contratos e convênios, e cuidar das questôes relativas à propriedade intelectual, é interligada ao setor de transferência de tecnologia (T\&T), e segue normas, diretrizes básicas, pareceres e modelos de instrumentos contratuais, repassados pela assessoria jurídica da Embrapa Sede.

Para a criação das embalagens anatômicas de frutas (inovação de processo), de acordo com o pesquisador entrevistado da Embrapa, a formalização e a assinatura do termo de convênio entre as partes atenderam aos padróes normais de exigências das instituiçóes, havendo, inicialmente, uma minuta sugestiva da aliança e, em seguida, a análise das questóes técnicas, de T\&T, e jurídica.

Dentre as cláusulas do termo gerado, havia algumas salvaguardas contratuais e questôes de transmissão de informações, e todos os envolvidos assinaram termos de confidencialidade. Nesse contexto, tanto o pesquisador da Embrapa quanto a entrevistada do IMA não demonstraram qualquer preocupação com o roubo de informaçóes na aliança, devido à confiança nos parceiros. Os cuidados relativos a esse assunto foram maiores na fase de teste dos protótipos, realizada na indústria somente após a submissão das patentes ao Instituto Nacional de Propriedade Intelectual (INPI).

A propósito, vale destacar que, segundo Wang et al. (2015), o risco de oportunismo é maior em empresas pertencentes a um mercado turbulento, porque elas estáo sempre em busca de novas ideias, fazendo com que aumentem, inclusive, os custos de proteção. No caso dessa aliança, os parceiros são instituiçóes de pesquisa, não conectadas ao mercado, o que torna as preocupaçóes desnecessárias.

Em relação às questóes de propriedade intelectual, ficou estabelecido que invençôes, processos, métodos, programas de computador ou inovaçóes técnicas, decorrentes do processo inovado, independentemente de serem ou não privilegiáveis ou patenteáveis, são de propriedade conjunta, com a divisão de tarefas e de lucros em proporçôes iguais entre os parceiros, não havendo qualquer divergência entre as partes.

Para o pesquisador Embrapa entrevistado, a experiência em alianças contribuiu para a prévia identificaçáo dos parceiros em potencial, com a finalidade de suprir a 
lacuna do conhecimento necessário à instituição. Isso corrobora a teoria que atribui à experiência a capacidade de identificar, iniciar e gerenciar parcerias, efetuando os ajustes necessários, a fim de alcançar benefícios colaborativos tangíveis e intangíveis (HEIMERIKS; DUYSTERS, 2007).

A Embrapa já havia estabelecido alianças prévias, tanto com o IMA quanto com o INT, sendo que a nova parceria foi motivada, segundo o entrevistado da Embrapa, pela possibilidade da realizaçáo de trabalhos interdisciplinares. Para a chefia de T\&T da Embrapa, há mais confiança nos parceiros com os quais já se trabalhou, o que resulta em maior agilidade nas atividades - característica da capacidade relacional -, visto que há maior conhecimento sobre a cultura, as crenças, a forma de atuação, os pontos fortes e fracos dos parceiros, o que facilita o gerenciamento e o fortalecimento da aliança e aumenta as chances de sua eficácia (ZOLLO; REUER; SINGH, 2002).

A pesquisadora entrevistada do IMA concorda com isso e ainda reforça: Quando se conhece o parceiro, sua expertise, seu laboratório, sua estrutura, sua condição e responsabilidade, tanto a comunicação quanto o trabalho ficam facilitados. Ela ressalta, todavia, que isso não significa uma diminuiçáo da complexidade da pesquisa, no caso de futuras alianças, porque será necessário refazer todo o estudo e o levantamento de informaçôes.

O IMA (principal parceiro da Embrapa nessa aliança), possui a Coordenação de Projetos, Pesquisas e Estudos Tecnológicos (Coppetec), uma fundação que auxilia na formalização e na gestão das alianças firmadas entre o instituto e outras instituiçôes. Por ser detentora de uma estrutura que conta com departamentos especializados na contratação de pessoas encarregadas, tanto pelas compras quanto pelo gerenciamento administrativo e financeiro de alianças, coube à Coppetec a gestáo administrativa e financeira dos três parceiros, na parceria analisada. Nesse sentido, segundo a literatura, instituiçóes com departamentos especializados tendem a ter um melhor desempenho (HEIMERIKS; DUYSTERS, 2007; KALE; SINGH, 2009), pois é possível centralizar, em um único local, a experiência adquirida de diferentes alianças, áreas e negócios (SLUYTS et al., 2011).

\subsection{Cultivar de Cevada BRS Quaranta: uma inovação de produto}

A Embrapa Trigo possui um grupo de pessoas ligadas ao setor de T\&T que disponibiliza, às unidades, minutas sugestivas de alianças, e é responsável pela formalização dos instrumentos jurídicos, normatizados pela Embrapa Sede, com o auxílio da assessoria jurídica local. 
Segundo o pesquisador entrevistado da Embrapa, somente depois do ano 2000 as alianças para $\mathrm{P} \& \mathrm{D}$ de cultivares (antes informais) passaram a adotar instrumentos jurídicos de formalização. Desde então, conforme a Coordenadora de Apoio à Inovação e Propriedade Intelectual da Embrapa, houve evolução e conscientização da sua importância para o estabelecimento de parcerias. Essa mudança de paradigma se deve a um esforço conjunto entre a diretoria e a assessoria jurídica da instituição para orientar os chefes das unidades Embrapa, atendendo, assim, à cobrança externa de órgãos reguladores, e, sobretudo, à cobrança interna, para evitar comportamentos oportunistas de parceiros. Como resultado, há maior atenção à instrução do processo, à negociação de contratos e à formalização, exigida pela lei.

Sem tais cuidados, de acordo com alguns estudiosos, podem ocorrer: a apropriação do conhecimento, a evasão das obrigaçôes, a quebra de contratos, o dimensionamento das capacidades ou o roubo de parceiros, propulsionando o oportunismo, um dos principais fatores capazes de dificultar o desempenho das alianças (JAP; ANDERSON, 2003). Nesse sentido, diversas açóes, realizadas na fase da formalização, com instrumentos jurídicos bem elaborados, contendo cláusulas preditoras de todos os tipos de situação, de salvaguardas contratuais, de direitos e deveres das partes, podem inibir esse tipo de comportamento.

A formalização de um instrumento para a celebração de uma aliança, para atividades P\&D, contudo, de acordo com o Chefe de T\&T da Embrapa, somente é realizada após algumas etapas, descritas a seguir.

$\mathrm{Na}$ fase de negociação, que ocorre por meio de telefonemas, troca de e-mails, conferências, reunióes e visitas, há a discussão de ideias entre a Embrapa e o futuro parceiro, para a definiçẫo do objetivo, das atividades, das responsabilidades, das questôes financeiras, etc. Após a anuência das partes, é necessário que haja a manifestação formal do interesse do parceiro na formação da aliança, além da entrega de alguns documentos preestabelecidos pela Embrapa, para comprovar a idoneidade da pessoa jurídica (como certidóes de regularidade), a inexistência de dívidas e sua atuação válida no mercado.

Vale ressaltar que as exigências são maiores quando se trata da formação de alianças com instituiçóes conectadas ao mercado, sendo que, além da documentação mencionada anteriormente, é preciso justificar, de forma clara, o porquê da escolha desse parceiro, a sua importância, e os resultados almejados, eliminando indícios de beneficiamento exclusivo de uma instituição. A Embrapa precisa, ainda, emitir uma nota técnica com a justificativa para a celebração dessa aliança e para a escolha do parceiro. No caso da aliança analisada por este estudo, formalizada com uma 
instituição não conectada ao mercado (Fapa) e outra conectada (AmBev), houve a necessidade de maior nível de formalização.

Concluída essa etapa, são discutidas, entre as instituiçôes envolvidas, as cláusulas da minuta do instrumento a ser firmado (Contrato de Cooperação Técnica) e o Plano Anual de Trabalho (PAT). O PAT contempla informaçóes dos materiais genéticos aportados pela Embrapa; o cronograma de atividades de responsabilidade e de desembolso de cada parte; os recursos financeiros; a quantidade de recursos humanos envolvidos; o nome, endereço e perfil das partes; e a indicaçáo dos locais, em que serão realizados os testes e as avaliaçôes, conforme destaca o Chefe de T\&T.

Além de toda a documentação inerente à justificativa técnica, no PAT, deve ser descrito exatamente o que cada um vai fazer, evitando, com isso, problemas com a propriedade intelectual e a exploração. Após essas definições e a concordância entre as partes, encaminha-se a minuta do instrumento, juntamente com o PAT, para as assessorias jurídicas das instituiçóes, a fim de que sejam emitidos o parecer e a aprovação.

Caso não haja óbices, o instrumento é encaminhado para assinatura dos parceiros e, posteriormente, publicado no Diário Oficial da Uniáo, sendo as vias encaminhadas à Embrapa Sede, para registro no Sistema Administrativo de Informaçóes Contratuais (Saic), que possibilita o acesso interno a todos os instrumentos jurídicos, celebrados entre a Embrapa e seus parceiros, por assunto e categoria, auxiliando a evitar a duplicaçáo de atividades de P\&D.

Após o retorno de uma das vias do contrato, ela é arquivada em setor específico, que controla a documentação gerada e os prazos de vigência. Tanto nessa fase quanto no decorrer da aliança, sempre que necessário, os pesquisadores podem se reportar a essas pessoas para solicitar auxílio.

A literatura destaca, nesse sentido, que toda aliança possui um ciclo de vida a ser seguido (KALE; SINGH, 2009). Em um primeiro momento, é relevante que as instituiçōes compartilhem informaçóes a respeito de seus recursos humanos e financeiros, além dos ativos que possui (SLUYTS; MARTENS; MATTHYSSENS, 2010). Posteriormente, devem ser definidas as atividades e responsabilidades de cada um, assim como a divisão dos lucros, receitas ou royalties (MASCARENHAS; KOZA, 2008).

De acordo com o pesquisador entrevistado da Embrapa, os parceiros externos consideram esse processo de formalização muito complexo, preferindo que ele fosse mais rápido e simples, como é no mundo privado: a burocracia exigida pela Embrapa, que visa proteger o bem público, acaba tornando os processos mais lentos; no entanto, a Embrapa se preocupa para que não haja vazamento de informaçôes ou uso indevido. 
No entanto, o Chefe de T\&T destaca que a formalização não está presente apenas na instituição, pois, quanto maior a empresa, maior o grau de complexidade desse instrumento e mais demorados os processos relacionados às alianças, sendo essa, por conseguinte, uma condição natural para se precaver de problemas futuros.

Para o pesquisador entrevistado da Embrapa, existe uma confiança mútua entre os parceiros, embora o contrato de parceria preveja cláusulas de propriedade intelectual, concedendo os direitos de propriedade das cultivares geradas, em sua totalidade, à Embrapa. As cláusulas de salvaguarda contratual impóem sigilo às partes, acerca das informaçôes técnicas da aliança celebrada, garantindo (ou não) a obtenção de privilégios e/ou uma eventual exploração econômica futura. Conforme a literatura destaca, empresas que conseguem utilizar mecanismos de governança adequados transmitem a segurança aos parceiros de que problemas poderão ser evitados, minimizados ou resolvidos, da melhor forma possível, e cada parte receberá o que lhe cabe, por direito, nessa colaboração.

Mesmo com a baixa frequência de conflitos, para o pesquisador da Embrapa, a experiência contribui para gerenciar aqueles que, eventualmente, podem surgir. Ter um parceiro de longa data é um fator facilitador, pois já se sabe como ele trabalha e para qual público os resultados têm que ser direcionados. A experiência e a reputaçáo da Embrapa contribuem para o fortalecimento da confiança entre os parceiros da aliança. De acordo com Mora-Valentin et al. (2004), as experiências prévias em alianças estratégicas, a boa reputação dos parceiros e a definição clara dos objetivos e comprometimento são elementos favoráveis ao sucesso de uma aliança.

A Fapa (principal parceiro da Embrapa nessa aliança) possui um departamento jurídico que verifica todas as questóes legais para a celebração de alianças estratégicas. A instituição possui um formulário que o pesquisador preenche com todas as informaçóes sobre o parceiro e as atividades de P\&D a serem desenvolvidas e, posteriormente, encaminha-o a uma pessoa específica na Fapa, que auxilia na formalizaçáo dos contratos. A seguir, esse documento é direcionado ao setor jurídico, que o analisa e aprova. Há, ainda, modelos-padróes de contratos para serem utilizados como base.

De modo geral, de acordo com o pesquisador entrevistado da Fapa, os termos de confidencialidade assinados entre os parceiros e as cláusulas contratuais são instrumentos para proteger que os dados sigilosos ou estratégicos da instituiçáo não saiam do âmbito da parceria.

Para o entrevistado da Fapa, a experiência possibilita expandir a rede de contatos, contribuindo, também, para a decisão da formação de uma nova aliança, sobretudo 
com um parceiro conhecido, pois sabe-se, de antemão, o que esperar dele, sua forma de atuação, se ele desenvolve as atividades conforme o que foi programado, bem como seus ativos e recursos.

\subsection{INOVA-Bti (inseticida biológico): uma inovação de produto}

O Embrapa Recursos Genéticos e Biotecnologia (Cenargen) possui duas pessoas que auxiliam na prospecção de clientes, de tecnologias e de demandas, compondo o Setor de Prospecção e Avaliação de Tecnologias (SPAT), que trata também de questôes relacionadas à propriedade intelectual. Há, ainda, outro setor, o de implementação, denominado Setor de Integração Tecnológica (SIT), responsável pela formalização das alianças (Chefe de T\&T).

A Chefia de T\&T destaca que é comum o surgimento de conflitos relacionados às cláusulas mais rígidas da Embrapa, assim como sobre a propriedade intelectual, no que diz respeito ao estabelecimento da divisão dos royalties. Por conta disso, recentemente, criou-se uma tabela com sugestóes e critérios para essa divisão. Tal documento tem facilitado a tomada de decisáo quanto a esse quesito, no momento da formulação dos contratos, os quais têm sido bem aceitos pelos parceiros nacionais.

A unidade possui um processo, denominado Gestão da Inovação, que envolve as chefias de P\&D, T\&T, o Comitê Técnico Interno (CTI) e o setor de Prospecção e Avaliação de Tecnologias (SPAT). Assim, toda vez que há intenção de formação de aliança, o processo é avaliado pelas chefias e pelos setores mencionados, e cada um faz a sua avaliação. Foi desenvolvido, inclusive, um fluxograma para a Gestáo da Inovação, que contém as etapas a serem seguidas, no momento da formalização (Chefe-Geral).

De acordo com a chefia de T\&T, antes da formalização de uma aliança, o contrato e o PAT são encaminhados ao Comitê Técnico Interno (CTI), que é composto por alguns pesquisadores da Embrapa, que emite um parecer, avaliando as questóes técnicas, tais como: se o prazo está adequado, se os recursos serão suficientes, se é uma pesquisa viável, entre outros assuntos. As sugestôes do CTI são analisadas e acatadas, caso sejam consideradas convenientes e, posteriormente, o processo é encaminhado ao jurídico.

Quando distintas unidades Embrapa possuem alianças com um mesmo parceiro, é criado um comitê-gestor, cuja função, segundo a Chefe de T\&T do Cenargen, é reunir e centralizar informaçōes de todas as atividades de P\&D realizadas entre as unidades da Embrapa e esse parceiro. Assim, eles organizam reunióes, em que 
os membros participantes apresentam as atividades realizadas, para a Embrapa ter o controle das informaçóes, fazer seu acompanhamento e evitar a duplicação de pesquisas e ações (Chefe de T\&T Cenargen).

A aliança para as atividades de P\&D entre o Cenargen, o IMAmt e a Comdeagro teve duração de um ano. A velocidade se deu em decorrência da situaçáo emergencial do país, que enfrentava casos do nascimento de crianças com microcefalia. Além disso, as duas instituições já possuíam os recursos necessários para o desenvolvimento do bioinseticida, e apenas necessitavam aprofundar as atividades de adaptação para o produto.

Com relação às salvaguardas contratuais, foram estabelecidas cláusulas-padrão da Embrapa, sobre sigilo e confidencialidade. Além disso, a pesquisadora entrevistada do Cenargen destacou a confiança entre os parceiros como um dos principais pontos para que uma aliança atinja seus objetivos: Mesmo que se tenha tudo no papel, se não houver confiança entre os envolvidos, fica mais difícil a realização das atividades.

Com relaçáo à propriedade intelectual, ficou estabelecido, no contrato, que quaisquer inventos, aperfeiçoamentos ou inovaçóes tecnológicas, nos termos da Legislação de Propriedade Intelectual, privilegiáveis ou não, adquiridos, produzidos ou transformados, oriundos da execução desse contrato, pertencerão a ambas as partes, nas proporçōes: Embrapa, 44\%; IMAmt, 28\%; e Comdeagro, 28\%. A Embrapa e o IMAmt se comprometeram, ainda, a conceder licença à Comdeagro, no que diz respeito às suas respectivas participaçóes sobre o direito de produçáo industrial e comercialização dos produtos gerados pela presente cooperação.

De acordo com o chefe geral do Cenargen, diversas alianças de P\&D haviam sido estabelecidas com o IMAmt, inclusive algumas ainda estão em andamento. Para ele, os principais benefícios relacionados à repetição de alianças se relacionam às adaptaçóes dos modelos dos instrumentos de formalização, seja com mais complexidade, seja com apenas as cláusulas-padrão, ou ainda, com somente as adaptações necessárias.

Além disso, há a possibilidade de fazer uma previsão mais realista dos custos envolvidos, pois, às vezes, eles são subestimados, assim como os gastos para P\&D. A repetição de parceiros dá maior agilidade às atividades, já que as partes se conhecem e sabem quais as limitaçóes de valores. Ela destaca, ainda, que as experiências amplas, com diferentes parceiros, vão dando subsídios para elaborar estratégias mais adequadas na negociação, na formalização de instrumentos e nas atividades a serem desenvolvidas em alianças posteriores.

A experiência em alianças auxilia na criação de mecanismos para evitar a reincidência de problemas, além de antecipar açóes que podem ser úteis futuramente. 
Por isso, o encaminhamento do processo ao CTI, antes da formalização de uma aliança, é importante. Por meio dele, é possível consultar outros pesquisadores, que não estấo envolvidos no projeto, para análise técnica e sugestóes, de acordo com a bagagem de conhecimentos adquiridos em outros projetos (Chefe de T\&T).

O IMAmt e a Comdeagro (principais parceiros da Embrapa nessa aliança) contrataram escritório terceirizado, que auxilia as instituições nas questóes relacionadas à celebração e à formalização de contratos. Eles redigem e analisam os instrumentos jurídicos, auxiliam no registro de patentes e cultivares, fazem traduçóes de instrumentos, etc. Por ser uma instituição privada, o IMAmt possui uma estrutura mais verticalizada, fazendo com que todas as decisóes para formação e formalização de alianças se deem de forma mais ágil.

Nas alianças formadas com a Embrapa, o IMAmt busca se adaptar às minutas contratuais padronizadas da instituição, porque o parceiro oportuniza a complementação de sua expertise. Tais minutas são analisadas pelo diretor do instituto que, posteriormente, faz seu encaminhamento ao escritório em São Paulo, que dá o parecer jurídico.

O IMAmt possui experiência na formação de alianças tanto com parceiros nacionais quanto internacionais. Inclusive, com a Embrapa, ele possui alianças já previamente estabelecidas, sendo que diversas estáo em andamento (21 com diferentes unidades da Embrapa). Além disso, três empregados do IMAmt estão atuando integralmente na Embrapa, na realizaçáo de P\&D. Para o pesquisador entrevistado, as principais vantagens na repetição de alianças,é que você tem o conhecimento sobre os trâmites internos, facilitando o atendimento das exigências e realização das atividades (Pesquisador entrevistado do IMAmt).

\section{Conclusões}

Os resultados agregados deste estudo demonstram que a Embrapa considera a colaboração externa com distintos parceiros importante para o desenvolvimento de inovaçóes (ROPER; LOVE; BONNER, 2017), mesmo sob o risco de surgirem eventuais barreiras significativas, quando os parceiros são heterogêneos, como custos mais altos com coordenação, dificuldades de comunicação (devido à distância cultural e à falta de entendimento compartilhado), e desacordos sobre a estratégia de invenção e de inovação (CUMMINGS; KIESLER, 2007).

No âmbito deste estudo, foi possível compreender e comprovar que a Embrapa atua oportunamente na estruturação de alianças estratégicas de P\&D, geradoras de 
inovaçóes agropecuárias, por meio do desenvolvimento de uma estrutura de governança apropriada, demonstrando uma expertise relacional, conforme proposto por Wang et al. (2015).

Ademais, ter uma estrutura de gestáo contribui para seguir e cumprir adequadamente o ciclo de vida da aliança (KALE; SINGH, 2009), visto que, em um primeiro momento, a Embrapa e seus parceiros escrevem um Plano Anual de Trabalho (PAT), compartilham informações a respeito de seus recursos humanos e financeiros, além dos ativos que possuem (SLUYTS; MARTENS; MATTHYSSENS, 2010); e, posteriormente, definem as atividades e responsabilidades de cada um, assim como a divisão dos lucros e de receitas, e a determinaçấo de um percentual de divisão de royalties futuros (MASCARENHAS; KOZA, 2008).

Essa capacidade da Embrapa, que impacta positivamente no desempenho das alianças, decorre da experiência adquirida da instituição (KOHTAMÄKI; RABETINO; MÖLLER, 2018), que foi aprimorando sua estrutura para a gestão de alianças, criando, para tanto, mecanismos, procedimentos, ferramentas e treinamentos (HEIMERIKS; DUYSTERS, 2007; SHAKERI; RADFAR, 2017). Além disso, ela desenvolveu sua capacidade de celebrar contratos, cujas cláusulas e acordos auxiliam na prevenção de riscos e de oportunismos futuros (ARGYRES; MAYER, 2007). Quando uma instituiçấo desenvolve a capacidade relacional, ela consegue utilizar os recursos dos parceiros para melhorar a inovação e os resultados de desempenho (NIESTEN; JOLINK, 2015; KOHTAMÄKI; RABETINO; MÖLLER, 2018). Sendo assim, destacam-se, a seguir, as principais análises conclusivas, obtidas nas três alianças aqui investigadas em profundidade.

A primeira aliança estratégica analisada foi formada entre a Embrapa Agroindústria de Alimentos, responsável por pesquisar e desenvolver inovaçóes direcionadas à agroindústria de alimentos; IMA, instituto de pesquisa público, referência no Brasil e na América Latina na área de ciência e tecnologia de polímeros; e o INT, instituto de pesquisa público, cujo foco é direcionado à inovação e ao desenvolvimento de tecnologias para os setores de petróleo e gás, energias renováveis, química verde, complexo industrial, saúde, defesa, tecnologias sociais e desenho industrial. Essa aliança resultou no desenvolvimento de embalagens anatômicas para frutas, que contribuem para a redução de perdas na manipulação, armazenamento e comercialização, e são produzidas com material de maior capacidade de decomposição na natureza.

A segunda aliança estratégica foi formada entre a Embrapa Trigo, unidade que realiza pesquisas para o desenvolvimento de inovaçóes, capazes de aumentar os rendimentos da produção agrícola de culturas de inverno; a AmBev, multinacional 
presente em 19 países, que é detentora de uma maltaria, cuja área de P\&D de cultivares de cevada atende aos padróes de malte exigidos por sua indústria; e a Fapa, que realiza P\&D para desenvolvimento de cultivares e híbridos, como milho, soja, trigo, cevada, além de pesquisas para aumentar a fertilidade do solo, a densidade das plantas, o manejo de doenças e de pragas, bem como de gerar inovaçóes tecnológicas e de maquinários. Essa aliança estratégica levou ao desenvolvimento da cultivar de cevada cervejeira Quaranta, cujo alto rendimento e qualidade, além da resistência genética à doença (oídio), reduzindo ou até mesmo dispensando a aplicação de herbicidas, contribuem para ganhos econômicos e geram menor impacto ambiental.

A terceira aliança estratégica analisada foi celebrada entre a Embrapa Cenargen, unidade que possui o terceiro maior banco de recursos genéticos do mundo, sendo atuante na pesquisa de programas de melhoramento genético, organismos geneticamente modificados, incluindo soja, milho, algodão e eucalipto, além de controle biológico, desenvolvimento de medicamentos, cultivo in vitro e biofábricas; o IMAmt, instituto que realiza P\&D, visando ao desenvolvimento de variedades (convencionais e transgênicas) de algodão mais produtivas e com fibras de melhor qualidade, sendo tolerantes às pragas que afetam as plantaçóes; e a Comdeagro, cooperativa que coloca à disposição dos associados as tecnologias desenvolvidas pelo IMAmt e parceiros, de forma mais ágil e com preço mais acessível. Essa aliança levou ao desenvolvimento do inseticida biológico INOVA-Bti, que auxilia no controle das larvas do mosquito Aedes aegypti, transmissor do vírus da Dengue, Chikungunya e Zika, contribuindo diretamente para melhorar a qualidade de vida das pessoas (pela diminuição da incidência das doenças).

Esta pesquisa contribui para o aumento do conhecimento teórico relacionado às alianças estratégicas, por meio de evidências empíricas, conforme demanda identificada por Sluyts et al. (2011), especialmente sobre a importância do desenvolvimento de estrutura de governança dentro das instituiçóes, como forma de aumentar a capacidade relacional e as chances de melhor desempenho das alianças, conforme os descritores listados a seguir (Quadro 3).

Como contribuiçãao gerencial, este estudo trouxe evidências sobre a relevância da avaliação da capacidade relacional das instituiçóes, visto que ela leva ao desenvolvimento de uma estrutura de governança, capaz de centralizar todos os conhecimentos e experiências adquiridos, e de mecanismos e ferramentas que tornam as alianças mais eficientes, afastando transtornos decorrentes de comportamentos oportunistas e insucessos. Ela auxilia, ainda, na criação de políticas para organizar e promover o intercâmbio de conhecimento, resultando em inovaçóes de maior significado (DUTRÉNIT; VERA-CRUZ, 2018). 


\section{QUADRO 3}

\section{Descritores da estrutura de governança, considerando três alianças estratégicas de P\&D, geradoras de inovaçóes da Embrapa}

\begin{tabular}{|c|c|c|c|}
\hline \multirow{6}{*}{ 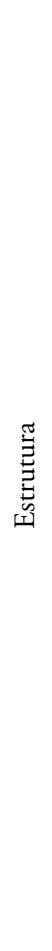 } & \multirow{2}{*}{$\begin{array}{l}\text { Aliança (1) } \\
\text { Embalagens } \\
\text { anatômicas para } \\
\text { frutas: inovação de } \\
\text { processo. }\end{array}$} & Embrapa & $\begin{array}{l}\text { Setor de gestão de contratos e convênios; empregados } \\
\text { especializados na formalizaçáo e na gestáo administrativa } \\
\text { de contratos, convênios e propriedade intelectual; normas, } \\
\text { diretrizes básicas, modelo de instrumentos jurídicos. }\end{array}$ \\
\hline & & IMA & $\begin{array}{l}\text { Possui uma instituiçáo que auxilia na formalizaçáo e na gestáo } \\
\text { das atividades das alianças; realizou compras de materiais, } \\
\text { equipamentos, insumos e contrataçáo de pessoas para a } \\
\text { execuçáo das atividades da aliança. }\end{array}$ \\
\hline & \multirow{2}{*}{$\begin{array}{l}\text { Aliança (2) } \\
\text { Cultivar de Cevada } \\
\text { BRS Quaranta: } \\
\text { inovação de produto. }\end{array}$} & Embrapa & $\begin{array}{l}\text { Pessoas especializadas para dar orientaçáo sobre a formalização } \\
\text { de alianças; fase de negociação; assessoria jurídica local; minutas } \\
\text { pré-aprovadas sugestivas; pessoas específicas para controle da } \\
\text { documentaçáo e da vigência do instrumento. }\end{array}$ \\
\hline & & Fapa & $\begin{array}{l}\text { Departamento jurídico; formulário para preenchimento de } \\
\text { informaçốes da aliança; pessoa que auxilia na formalização do } \\
\text { instrumento; minutas pré-aprovadas sugestivas. }\end{array}$ \\
\hline & \multirow[t]{2}{*}{$\begin{array}{l}\text { Aliança (3) } \\
\text { INOVA-Bti } \\
\text { (inseticida biológico): } \\
\text { inovação de produto. }\end{array}$} & Embrapa & $\begin{array}{l}\text { Setor que auxilia na prospecção de clientes, de tecnologias, de } \\
\text { demandas e nas questóes de propriedade intelectual; utilização } \\
\text { de tabela para cálculo de \% de royalties; fluxograma de gestão } \\
\text { da inovação; Comitê Técnico Interno para avaliação técnica; } \\
\text { constituição do comitê-gestor das alianças na Embrapa, para } \\
\text { acompanhamento de todas as parcerias formadas entre o } \\
\text { IMAmt e as unidades da Embrapa. }\end{array}$ \\
\hline & & IMAmt & $\begin{array}{l}\text { Escritório terceirizado, que auxilia o instituto em todas as } \\
\text { questóes relacionadas à formalizaçáo, ao acompanhamento dos } \\
\text { contratos, ao registro de patentes e de cultivares, e à traduçấo } \\
\text { de documentos. }\end{array}$ \\
\hline \multirow{6}{*}{ 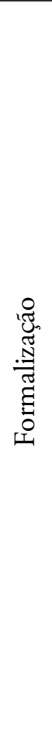 } & \multirow{2}{*}{$\begin{array}{l}\text { Aliança (1) } \\
\text { Embalagens } \\
\text { anatômicas para } \\
\text { frutas: inovação de } \\
\text { processo. }\end{array}$} & Embrapa & $\begin{array}{l}\text { Termo de convênio; cláusulas de salvaguardas contratuais; } \\
\text { cláusula de divisáo de propriedade intelectual em partes iguais; } \\
\text { termo de confidencialidade. }\end{array}$ \\
\hline & & IMA & $\begin{array}{l}\text { Termo de convênio; cláusulas de salvaguardas contratuais; } \\
\text { cláusula de divisão de propriedade intelectual em partes iguais; } \\
\text { termo de confidencialidade. }\end{array}$ \\
\hline & \multirow[t]{2}{*}{$\begin{array}{l}\text { Aliança (2) } \\
\text { Cultivar de Cevada } \\
\text { BRS Quaranta: } \\
\text { inovação de produto. }\end{array}$} & Embrapa & $\begin{array}{l}\text { Fase de negociação; solicitação de documentação para } \\
\text { comprovaçáo da idoneidade da empresa; justificativa da escolha } \\
\text { do parceiro; contrato de Cooperaçáo Técnica; elaboração de } \\
\text { um Plano Anual de Trabalho; termo de convênio; cláusulas de } \\
\text { salvaguardas contratuais; cláusula de propriedade intelectual; } \\
\text { controle dos instrumentos no SAIC. }\end{array}$ \\
\hline & & Fapa & $\begin{array}{l}\text { Analisam as minutas sugestivas da Embrapa; assinam termos } \\
\text { de confidencialidade. }\end{array}$ \\
\hline & \multirow{2}{*}{$\begin{array}{l}\text { Aliança (3) } \\
\text { INOVA-Bti } \\
\text { (inseticida biológico): } \\
\text { inovação de produto. }\end{array}$} & Embrapa & $\begin{array}{l}\text { Solicitação de documentação para comprovação da idoneidade } \\
\text { da empresa; cláusulas de salvaguardas contratuais; cláusulas } \\
\text { com divisão de percentual de royalties. }\end{array}$ \\
\hline & & IMAmt & $\begin{array}{l}\text { Possui suas minutas contratuais, mas busca se adaptar às } \\
\text { minutas dos parceiros; para a aliança, foram assinados termos } \\
\text { de confidencialidade. }\end{array}$ \\
\hline
\end{tabular}




\section{QUADRO 3}

\section{Descritores da estrutura de governança, considerando três alianças} estratégicas de $P \& D$, geradoras de inovaçóes da Embrapa

(continuação)

\begin{tabular}{|c|c|c|c|}
\hline \multirow{6}{*}{ 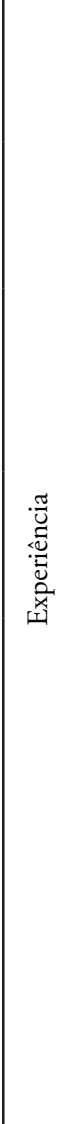 } & \multirow{2}{*}{$\begin{array}{l}\text { Aliança (1) } \\
\text { Embalagens } \\
\text { anatômicas para } \\
\text { frutas: inovação de } \\
\text { processo. }\end{array}$} & Embrapa & $\begin{array}{l}20 \text { alianças com outras instituiçóes para atividades de P\&D } \\
\text { estấo vigentes na Embrapa Agroindústria de Alimentos; já } \\
\text { haviam sido estabelecidas parcerias prévias entre Embrapa, } \\
\text { IMA e INT. }\end{array}$ \\
\hline & & IMA & $\begin{array}{l}\text { Experiência prévia na formação de alianças estratégicas com } \\
\text { outras instituiçóes para atividades de P\&D; Petrobrás era um } \\
\text { de seus principais parceiros; já havia estabelecido parcerias } \\
\text { prévias com a Embrapa e o INT. }\end{array}$ \\
\hline & \multirow{2}{*}{$\begin{array}{l}\text { Aliança (2) } \\
\text { Cultivar de Cevada } \\
\text { BRS Quaranta: } \\
\text { inovação de produto. }\end{array}$} & Embrapa & $\begin{array}{l}80 \text { instrumentos vigentes, celebrados com instituiçóes das mais } \\
\text { distintas naturezas (fundaçóes, cooperativas, universidades, } \\
\text { produtores rurais, organizaçôes estaduais de pesquisa, } \\
\text { institutos, etc.); melhor compreensấo da demanda de mercado; } \\
\text { repasse de confiança aos parceiros. }\end{array}$ \\
\hline & & Fapa & $\begin{array}{l}\text { Possui experiência na celebração de alianças com distintas } \\
\text { instituiçốes; seleçấo de parceiros; a experiência auxilia na } \\
\text { expansão de redes de contatos e na decisão para a repetiçâo } \\
\text { de parcerias. }\end{array}$ \\
\hline & \multirow{2}{*}{$\begin{array}{l}\text { Aliança (3) } \\
\text { INOVA-Bti } \\
\text { (inseticida biológico): } \\
\text { inovaçáo de produto. }\end{array}$} & Embrapa & $\begin{array}{l}\text { Diversas alianças vigentes; adaptação das minutas contratuais; } \\
\text { maior agilidade nos processos de formalização de aliança; } \\
\text { elaboração de estratégias mais adequadas, seja na negociação, } \\
\text { formalização de instrumentos, seja nas atividades a serem } \\
\text { desenvolvidas em alianças posteriores; auxílio na criaçáo } \\
\text { de mecanismos para evitar a reincidência de problemas; há } \\
21 \text { alianças vigentes com o IMAmt, em diversas unidades } \\
\text { Embrapa. }\end{array}$ \\
\hline & & IMAmt & $\begin{array}{l}\text { Experiência na formação de alianças, tanto com parceiros } \\
\text { nacionais quanto internacionais; principais vantagens na } \\
\text { repetição de parcerias é que se tem o conhecimento sobre os } \\
\text { trâmites internos, facilitando o atendimento das exigências e da } \\
\text { realizaçáo das atividades; há parcerias prévias entre a Embrapa e } \\
\text { o IMAmt; atualmente, } 21 \text { alianças estáo vigentes. }\end{array}$ \\
\hline
\end{tabular}

Fonte: Elaborado pelos autores.

Este estudo também sinaliza o crescente interesse em discussóes acerca da importância da Embrapa e dos seus parceiros, no que tange ao investimento em atividades de marketing e logística, e na construção de ativos intangíveis. Isso estimula o debate a respeito do fortalecimento e da autonomia das organizaçóes públicas de pesquisa agrícola e do progresso científico e tecnológico do país.

Como futuras pesquisas, sugere-se a ampliação da análise, a partir de um número maior de instituições que celebram alianças estratégicas para a realização de P\&D e de inovaçóes agropecuárias. Por se tratar de uma pesquisa qualitativa, vale, por fim, destacar que este estudo apresenta como limitação a seleção restrita 
do número de casos (três alianças, envolvendo oito instituições), não sendo, assim, possível a sua generalização para outras alianças de $\mathrm{P} \& \mathrm{D}$, para o desenvolvimento de inovação, nem de seus resultados, em relação às outras unidades da Embrapa e de seus parceiros.

\section{Referências}

ALMEIDA, J.M; COSTA, P.R. Development of Relational Capability in Technology-based Companies in the Information and Communication Technology Sector. International Journal of Managerial Studies and Research, v. 5, p. 119-126, 2017.

APPIO, F.P. et al. Search mechanisms and innovation: An analysis across multiple perspectives. Technological Forecasting and Social Change, v. 120, p. 103-116, 2017.

ARGYRES, N.; MAYER, K.J. Contract design as a firm capability: An integration of learning and transaction cost perspectives. Academy of Management Review, v. 32, n. 4, p. 1060-1077, 2007.

BRASIL. Ministério da Agricultura e Reforma Agrária. Portaria n. 193, de 7 de agosto de 1992. Institui o Sistema Nacional de Pesquisa Agropecuária. Diário Oficial da União: seçâo 1, Brasília, DF, p. 51, 10 ago. 1992.

CARAYOL, N. Objectives, agreements and matching in science-industry collaborations: Reassembling the pieces of the puzzle. Research policy, v. 32, n. 6, p. 887-908, 2003.

CHESBROUGH, H. Open innovation: a new paradigm for understanding industrial innovation. In: CHESBROUGH, H.; VANHAVERBEKE, W.; WEST, J. (ed.). Open innovation: Researching a new paradigm. Oxford: Oxford University Press, 2006. p. 1-12.

COSTA, P.R.; PORTO, G.S. Elementos Tecnológicos Determinantes das Capacidades Dinâmicas de Inovação e Cooperação: Um Estudo com as Multinacionais Brasileiras. Revista Ibero-americana de Estratégia, v. 13, n. 3, p. 77-93, 2014.

CRESWELL, J. Research design: Qualitative, quantitative, and mixed methods approaches. London: SAGE Publications, 2017.

CUMMINGS, J.N.; KIESLER, S. Coordination costs and project outcomes in multiuniversity collaborations. Research Policy, v. 36, n. 10, p. 1620-1634, 2007.

DING, R.; DEKKER, H.C.; GROOT, T. Risk, partner selection and contractual control in interfirm relationships. Management Accounting Research, v. 24, n. 2, p. 140-155, 2013. 
DOSSA, A.A.; SEGATTO, A.P. Pesquisas cooperativas entre universidades e institutos públicos no setor agropecuário brasileiro: um estudo na Embrapa. Revista de Administração Pública, v. 44, n. 6, p. 1327-1352, 2010.

DUTRÉNIT, G.; VERA-CRUZ, A.O. Fostering innovation in the agriculture sector: The case of intermediary organisations in Mexico. MedCrave, v. 2, n. 2, p. 95-107, 2018.

DU, J.; LETEN, B.; VANHAVERBEKE, W. Managing open innovation projects with science-based and market-based partners. Research Policy, v. 43, n. 5, p. 828-840, 2014.

DYER, J.H.; SINGH, H. The relational view: Cooperative strategy and sources of interorganizational competitive advantage. Academy of Management Review, v. 23, n. 4, p. 660-679, 1998.

EMBRAPA. Embrapa em números. Brasília, DF: Embrapa, 2019. Disponível em: https:// www.embrapa.br/embrapa-em-numeros. Acesso em: 18 ago. 2020.

ETZKOWITZ, H. Innovation Lodestar: The entrepreneurial university in a stellar knowledge firmament. Technological Forecasting and Social Change, v. 123, p. 122-129, 2017.

FABRIZIO, K.R. Absorptive capacity and the search for innovation. Research policy, v. 38, n. 2, p. 255-267, 2009.

FAEMS, D.; VAN LOOY, B.; DEBACKERE, K. Interorganizational collaboration and innovation: Toward a portfolio approach. Journal of product innovation management, v. 22, n. 3, p. 238-250, 2005.

FIGUEIREDO, P. New challenges for public research organisations in agricultural innovation in developing economies: Evidence from Embrapa in Brazil's soybean industry. The Quarterly Review of Economics and Finance, v. 62, p. 21-32, 2016.

GODOY, A.S. Introdução à pesquisa qualitativa e suas possibilidades. Revista de administração de empresas, v. 35, n. 2, p. 57-63, 1995.

GULATI, R.; SINGH, H. The architecture of cooperation: Managing coordination costs and appropriation concerns in strategic alliances. Administrative science quarterly, v. 43. n. 4, p. 781-814, 1998.

HEIMERIKS, K.H.; DUYSTERS, G. Alliance capability as a mediator between experience and alliance performance: An empirical investigation into the alliance capability development process. Journal of Management Studies, v. 44, n. 1, p. 25-49, 2007.

HELFAT, C.E. et al. Dynamic capabilities: Understanding strategic change in organizations. New Jersey: John Wiley \& Sons, 2009. 
HOANG, H.; ROTHAERMEL, F.T. The effect of general and partner-specific alliance experience on joint R\&D project performance. Academy of Management Journal, v. 48, n. 2, p. 332-345, 2005.

JAP, S.D.; ANDERSON, E. Safeguarding interorganizational performance and continuity under ex post opportunism. Management science, v. 49, n. 12, p. 1684-1701, 2003.

KALE, P.; SINGH, H. Managing strategic alliances: what do we know now, and where do we go from here? The Academy of Management Perspectives, v. 23, n. 3, p. 45-62, 2009.

KALE, P.; DYER, J.H.; SINGH, H. Alliance capability, stock market response, and longterm alliance success: the role of the alliance function. Strategic management journal, v. 23, n. 8, p. 747-767, 2002.

KAUPPILA, O-P. Alliance management capability and firm performance: Using resourcebased theory to look inside the process black box. Long Range Planning, v. 48, n. 3, p. $151-167,2015$.

KOHTAMÄKI, M.; RABETINO, R.; MÖLLER, K. Alliance capabilities: A systematic review and future research directions. Industrial Marketing Management, v. 68, p. 188$201,2018$.

LETEN, B. et al. IP models to orchestrate innovation ecosystems: IMEC, a public research institute in nano-electronics. California management review, v. 55, n. 4, p. 51-64, 2013.

LHUILLERY, S.; PFISTER, E. R\&D cooperation and failures in innovation projects: Empirical evidence from French CIS data. Research Policy, v. 38, n. 1, p. 45-57, 2009.

LUO, Y.; TAN, J. Structuring international joint ventures: how should contractual design be aligned with environmental conditions? Management International Review, v. 43, n. 2, p. 185-211, 2003.

MARCONI, M. de A. et al. Técnicas de pesquisa. 6. ed. São Paulo: Atlas. 2006. v. 4.

MASCARENHAS, B.; KOZA, M.P. Develop and nurture an international alliance capability. Thunderbird International Business Review, v. 50, n. 2, p. 121-128, 2008.

MILAGRES, R.; REZENDE, O.; SILVA, S.A.G. da. Papel e posição do departamento de alianças: caso Embrapa. Revista de Administração Pública, v. 51, n. 3, p. 431-450, 2017.

MORA-VALENTIN, E.M.; MONTORO-SANCHEZ, A.; GUERRAS-MARTIN, L.A. Determining factors in the success of $R \& D$ cooperative agreements between firms and research organizations. Research Policy, v. 33, n. 1, p. 17-40, 2004. 
NIESTEN, E.; JOLINK, A. The impact of alliance management capabilities on alliance attributes and performance: A literature review. International Journal of Management Reviews, v. 17, n. 1, p. $69-100,2015$.

PATTERSON, W.; AMBROSINI, V. Configuring absorptive capacity as a key process for research intensive firms. Technovation, v. 36, p. 77-89, 2015.

POPPO, L.; ZENGER, T. Do formal contracts and relational governance function as substitutes or complements? Strategic Management Journal, v. 23, n. 8, p. 707-725, 2002.

POWELL, W.W.; KOPUT, K.W.; SMITH-DOERR, L. Interorganizational collaboration and the locus of innovation: Networks of learning in biotechnology. Administrative science quarterly, v. 41, n. 1, p. 116-145, 1996.

ROPER, S.; LOVE, J.H.; BONNER, K. Firms' knowledge search and local knowledge externalities in innovation performance. Research Policy, v. 46, n. 1, p. 43-56, 2017.

SHAKERI, R.; RADFAR, R. Antecedents of strategic alliances performance in biopharmaceutical industry: A comprehensive model. Technological Forecasting and Social Change, v. 122, p. 289-302, 2017.

SCHILKE, O.; COOK, K.S. Sources of alliance partner trustworthiness: Integrating calculative and relational perspectives. Strategic Management Journal, v. 36, n. 2, p. 276$297,2015$.

SCHILKE, O.; GOERZEN, A. Alliance management capability: An investigation of the construct and its measurement. Journal of Management, v. 36, n. 5, p. 1192-1219, 2010.

SLUYTS, K.; MARTENS, R.; MATTHYSSENS, P. How to build alliance capability: A life cycle approach. In: SANCHEZ, R.; HEENE, A. (ed.). Enhancing Competences for Competitive Advantage (Advances in Applied Business Strategy) Binley, England: Emerald Group Publishing Limited, 2010. v. 12. p. 173-200.

SLUYTS, K. et al. Building capabilities to manage strategic alliances. Industrial Marketing Management, v. 40, n. 6, p. 875-886, 2011.

SORRENTINO, F.; GARRAFFO, F. Explaining performing R\&D through alliances: Implications for the business model of Italian dedicated biotech firms. Journal of Management \& Governance, v. 16, n. 3, p. 449-475, 2012.

VIEIRA FILHO, J.E.R.; VIEIRA, A.C.P. A Inovação da Agricultura Brasileira: uma reflexão a partir da análise dos certificados de proteção de cultivares Brasília, DF: Repositório do Conhecimento do Instituto de Pesquisa Econômica Aplicada (IPEA), 2013. (Texto para Discussão, n. 1866). 
WALSH, J.P.; LEE, Y.N.; NAGAOKA, S. Openness and innovation in the US: Collaboration form, idea generation and implementation. Research Policy, v. 45, n. 8, p. 1660-1671, 2016. WANG, G. et al. The effects of firm capabilities on external collaboration and performance: The moderating role of market turbulence. Journal of Business Research, v. 68, n. 9, p. 19281936, 2015.

ZAMBERLAN, L. et al. Pesquisa em ciências sociais aplicadas. Ijuí: Unijuí, 2014.

ZHANG, S.; LI, N.; LI, J. Redefining relational rent. Technological Forecasting and Social Change, v. 117, n. 4, p. 315-326, 2017.

ZOLLO, M.; REUER, J.J.; SINGH, H. Interorganizational routines and performance in strategic alliances. Organization science, v. 13, n. 6, p. 701-713, 2002.

\section{Contribuição das autoras}

A. Fundamentação teórico-conceitual e problematização: Taísa Scariot Preusler, Priscila Rezende da Costa, Tatiane Baseggio Crespi

B. Pesquisa de dados e análise estatística: Taísa Scariot Preusler, Priscila Rezende da Costa, Tatiane Baseggio Crespi

C. Elaboração de figuras e tabelas: Taísa Scariot Preusler, Priscila Rezende da Costa, Tatiane Baseggio Crespi

D. Elaboração e redação do texto: Taísa Scariot Preusler, Priscila Rezende da Costa, Tatiane Baseggio Crespi

E. Seleção das referências bibliográficas: Taísa Scariot Preusler, Priscila Rezende da Costa, Tatiane Baseggio Crespi

Conflito de interesse: as autoras declaram não haver conflito de interesse.

Fonte de financiamento: as autoras declararam não haver fonte de financiamento

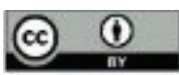

Este é um artigo publicado em acesso aberto (Open Access) sob a licença Creative Commons Attribution CC-BY, que permite uso, distribuição e reprodução em qualquer meio, sem restriçôes desde que o trabalho original seja corretamente citado. 